\title{
PENGARUH KOMPOSISI TERHADAP KARAKTERISTIK BRIKET KOMBINASI ARANGTEMPURUNG KELAPA DAN ARANG BAMBU
}

\author{
Ihsan dan Muh. Asrianto $\mathrm{T}^{1}$ \\ 1Jurusan Fisika, Fakultas Sains dan Teknologi, UIN Alauddin Makassar \\ Email:ihsanphysics@uin-alauddin.ac.id
}

\begin{abstract}
This research aims to determine the influence of variations of coconut shell charcoal and bamboo charcoal on briquette characteristics, thus obtained optimum composition that produces briquette with the best characteristic. This research is a laboratory experimentation study, with free variables being charcoal compositions, and bound variables are characteristic briquettes consisting of: Heat value, moisture content, and ignition length. The results showed that variations in the composition of briquette from coconut charcoal and bamboo charcoal influenced briquette characteristics, moisture value, moisture content, and the length of time of ignition. The highest heat value is obtained on the composition of $10 \%$ of bamboo charcoal and $90 \%$ of coconut shell Charcoal is $7110.73 \mathrm{cal} / \mathrm{G}$ with a water content of $4.82 \%$ and the length of time of 150.45 minutes.
\end{abstract}

Keywords: Bamboo charcoal, coconut shell charcoal, briquette, and Calor value.

\section{PENDAHULUAN}

\section{Latar Belakang}

Seiring dengan perkembangan kebudayaan manusia mengakibatkan pula meningkatnya kebutuhan akan energi. Sumber energi utama yang digunakan saat ini adalah minyak bumi dan gas alam. Sementara cadangan minyak bumi dan gas alam merupakan sumber energi yang tidak dapat diperbaharui dan saat ini jumlahnya semakin menipis. Berdasarkan data SKK(Satuan Kerja Khusus) Migas, data produksi minyak Indonesia per Mei 2016 adalah 832.000 barrel per hari (BPOD), setara sekitar 1 persen produksi minyak dunia. Adapun produksi harian gas mencapai 8.215 MMSCFD. Sisa yang ada, menurut analisis yang dirujuk SKK Migas hanya akan bertahan hingga 10 tahun ke depan untuk tingkat pemakaian yang tak berubah dari sekarang. Padahal, konsumsi migas Indonesia rata-rata meningkat sekitar 8 persen per tahun, dengan angka saat ini sekitar 1,6 juta barrel per hari (Kompas.com, 2016).

Oleh karena itu kita dituntut untuk memikirkan sumber energi alternatif yang dapat diperbaharui. Salah satu sumber energi alternatif yang dapat digunakan yaitu energi biomassa. Energi biomassa merupakan sumber energi alternatif yang perlu mendapat prioritas dalam pengembangannya dibandingkan dengan sumber energi 
yang lain. Di sisi lain, Indonesia sebagai negara agraris banyak menghasilkan limbah pertanian yang kurang termanfaatkan. Limbah pertanian tersebut dapat diolah menjadi suatu bahan bakar padat buatan yang digunakan sebagai pengganti bahan bakar alternatif yang disebut briket bioarang. Penelitian tentang briket bioarang telah banyak dilakukan dengan berbagai macam limbah dan karakteristik yang dihasilkan. Masing-masing briket mempunyai karakteristik masing-masing dan masih memerlukan penelitian lebih lanjut untuk pengembangannya.

Beberapa jenis limbah pertanian yang banyak diteliti antara lain; limbah tempurung kelapa, limbah sekam padi, enceng gondok, ampas tebu, tongkol jagung, dan lain-lain. Berdasarkan hasil penelitian tentang kualitas briket biomassa dari tempurung kelapa dan sekam padi diperoleh bahwa efisiensi termal dari briket sekam padi dan tempurung kelapa masing-masing sebesar $31.13 \%$ dan $22.28 \%$ (Idni Qistina dkk, 2016). Berdasarkan penelitian tentang briket dari variasi tempurung kelapa, enceng gondok, dan ampas tebu diperoleh bahwa komposisi terbaik terletak pada perbandingan komposisi arang tempurung kelapa : arang ampas tebu : arang eceng gondok adalah 6:1:1 ukuran 40 mess, dan karakteristik briket arang terbaik yang dihasilkan adalah: kadar air sebesar 1,90\%, kadar zat menguap (volatile matter) sebesar 16,30\%, kadar abu sebesar 2,65\%, kadar karbon terikat (fixed carbon) sebesar 78,80\% dan nilai kalor adalah sebesar 6156,25 kalori (Monica CR dkk, 2012). Sedangkan pembuatan briket dari tongkol jagung dan sekam padi diperoleh bahwa komposisi yang paling optimum yaitu pada komposisi tongkol jagung dan sekam padi $75 \%$ : 25\% dengan kadar karbon terikat sebesar $41,49 \%$ dan nilai kalor sebesar 5.636,3 cal/gram (Budi NW dkk, 2016).

Berdasarkan data-data penelitian tersebut, mutu briket yang dihasilkan masih perlu ditingkatkan. Disamping mutu yang ditingkatkan, ketersediaan bahan baku juga harus dipertimbangkan. Hal inilah yang menjadi motivasi peneliti yaitu menghasilkan briket dengan karakteristik/mutu yang bagus dengan bahan yang mudah diperoleh dan melimpah. Dan salah satu limbah yang masih melimpah ketersediaannya adalah limbah tempurung kelapa. Pohon kelapa yang menghasilkan limbah tempurung kelapa merupakan tanaman yang keberadaannya hampir di seluruh pelosok. Material lain yang memiliki karakteristik yang dapat digunakan adalah arang bambu. Arang bambu memiliki nilai kalor yang lebih baik dari tempurung kelapa. Berdasarkan pengujian laboratorium, arang bambu dapat memiliki kandungan karbon sebesar $89,11 \%$ dengan nilai kalor sebesar 7346 $\mathrm{kal} / \mathrm{gram}$. Disamping itu, pohon bambu juga memiliki penyebaran di seluruh pelosok dan mempunyai pertumbuhan dan regenerasi yang cepat.

\section{Tujuan Penelitian}

Berdasarkan latar belakang di atas, peneliti bermaksud memadukan antara arang tempurung kelapa dan arang bambu dengan variasi komposisi sehingga diperoleh komposisi optimum yang menghasilkan briket dengan karakteristik yang terbaik.

\section{METODE PENELITIAN}

Penelitian ini adalah penelitian eksperimen laboratorium, dengan variabel bebas adalah komposisi arang, dan variabel terikat adalah karakteristik briket yang 
terdiri dari: nilai kalor, kadar air, dan lama penyalaan. Adapun tahapan penelitian sebagai berikut:

a. Penyiapan Bahan Baku

Bahan baku yang disiapkan berupa tempurung kelapa dan bambu dibersihkan dari material-material tidak berguna, seperti batu dan sebagainya. Kemudian bahan baku dikeringkan dibawah sinar matahari sebelum dikarbonisasi. b. Proses Karbonisasi

Proses pengarangan atau karbonisasi ini dapat dilakukan dengan menggunakan drum bekas yang telah bersih. Drum tersebut terlebih dahulu diberi lubang-lubang kecil dengan paku pada bagian dasar agar tetap ada udara yang masuk ke dalam drum.

c. Pengecilan Ukuran Bahan

Arang yang telah didapatkan selanjutnya dihaluskan dan dilakukan pengayakan dengan ukuran 40 mesh. Pengecilan ukuran bahan baku hingga halus bertujuan untuk mendapatkan bahan briket yang bagus.

d. Pencampuran

Bahan perekat dicampur dengan arang yang telah halus sampai membentuk semacam adonan. Bahan perekat ini dimaksudkan agar briket tidak mudah pecah ketika dibakar. Adapun perbandingan arang bambu dan arang tempurung kelapa yang digunakan adalah 40:60, 30:70, 20:80, dan 10:90

e. Pencetakan

Bahan-bahan yang telah tercampur secara merata kemudian dilakukan pencetakan adonan. Bentuk cetakan yang akan dibuat bisa disesuaikan dengan kebutuhan. Caranya adalah adonan dimasukkan ke dalam cetakan, kemudian ditekan atau dikempa hingga mampat.

f. Pengeringan

Briket yang telah dicetak langsung dikeringkan, agar briket cepat menyala dan tidak berasap. Pengeringan dilakukan dengan menggunakan oven dengan suhu $110^{\circ}$ selama 20 jam.dapat dilakukan di bawah sinar matahari atau dengan sarana pengeringan buatan menggunakan oven.

g. Pengujian briket/uji karakteristik.

Uji karakteristik yang dilakukan dalam penelitian ini meliputi uji nilai kalor, kadar air, dan lama penyalaan.

\section{HASIL DAN PEMBAHASAN}

\section{Hasil Penelitian}

Hasil pengukuran nilai kalor, kadar air, dan lama penyalaan disajikan dalam tabel 1 berikut: 
Tabel 1. Hasil pengukuran nilai kalor, kadar air, dan lama pembakaran

\begin{tabular}{|c|c|c|c|c|c|}
\hline \multirow[b]{2}{*}{$\begin{array}{l}\text { Ukuran } \\
\text { Partikel }\end{array}$} & \multicolumn{2}{|c|}{ Variasi komposisi } & \multirow[b]{2}{*}{$\begin{array}{l}\text { Nilai kalor } \\
\text { (kal/gram) }\end{array}$} & \multirow[b]{2}{*}{$\begin{array}{l}\text { Lama } \\
\text { pembakaran } \\
\text { (menit) }\end{array}$} & \multirow[b]{2}{*}{ Kadar air (\%) } \\
\hline & $\begin{array}{l}\text { Arang } \\
\text { bambu }\end{array}$ & $\begin{array}{c}\text { Arang } \\
\text { tempurung } \\
\text { kelapa }\end{array}$ & & & \\
\hline \multirow{4}{*}{$\begin{array}{c}40 \\
\text { mesh }\end{array}$} & $40 \%$ & $60 \%$ & $6.367,2078$ & 173,98 & 5.90 \\
\hline & $30 \%$ & $70 \%$ & $6.442,7523$ & 183,55 & 5.93 \\
\hline & $20 \%$ & $80 \%$ & $6.858,2125$ & 155,53 & 4.82 \\
\hline & $10 \%$ & $90 \%$ & $7.110,7288$ & 150,45 & 3.80 \\
\hline
\end{tabular}

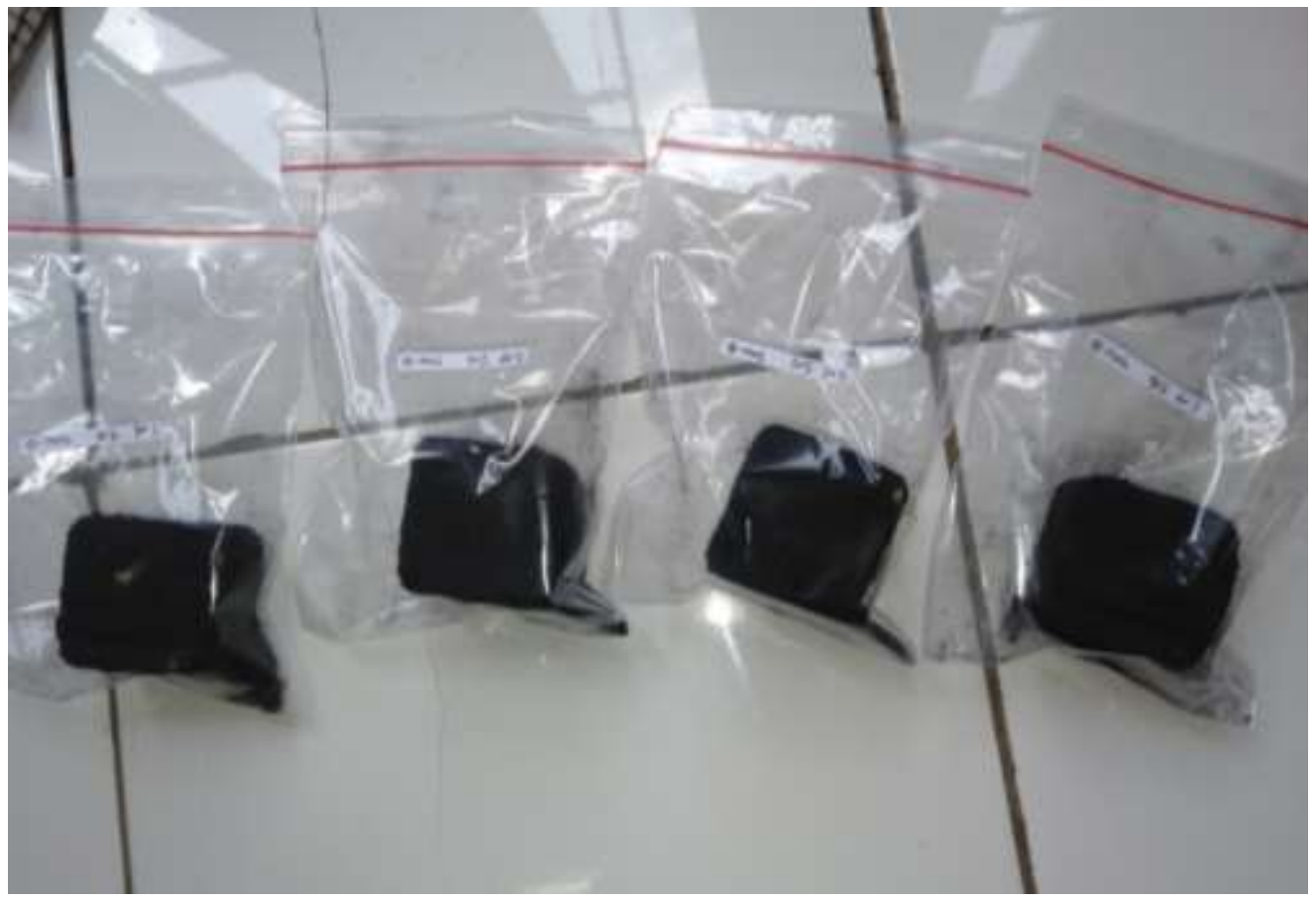

Gambar 1. Briket kombinasi arang bambu dan tempurung kelapa

\section{Pembahasan}

1. Nilai kalor briket

Hasil pengujian nilai kalor dengan menggunakan boom calorimeter ditunjukkan pada Gambar 2 berikut: 


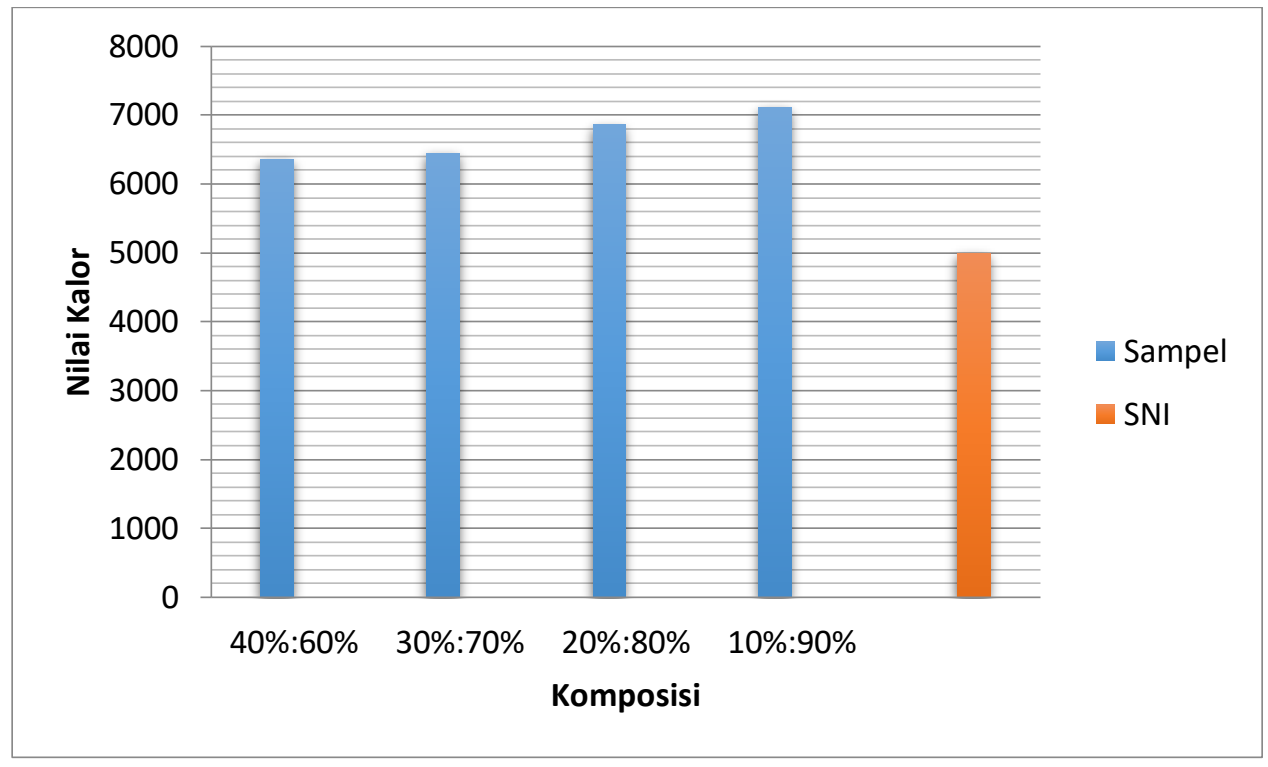

Gambar 2. Grafik hubungan antara komposisi briket terhadap nilai kalor pada ukuran partikel yang berbeda

Pengukuran nilai kalor merupakan salah satu parameter penting dalam pembuatan briket. Nilai kalor menunjukkan ukuran nilai panas pembakaran yang dihasilkan oleh briket.

Berdasarkan grafik tersebut, terlihat bahwa komposisi penyusun briket mempengaruhi nilai kalor briket. Nilai kalor tertinggi diperoleh pada komposisi $10 \%$ arang bambu dan $90 \%$ arang tempurung kelapa yaitu sebesar 7110,73 kal/g. Secara rata-rata terlihat bahwa penambahan arang bambu menyebabkan berkurangnya nilai kalor. Sehingga komposisi arang bambu yang optimum adalah sebesar $10 \%$. Hal ini diduga bahwa bambu memiliki daya serap yang tinggi, sehingga dengan penambahan bamu menyebabkan nilai kalor yang semakin kecil.

Berdasarkan pengujian nilai kalor, nilai kalor yang dihasilkan oleh briket kombinasi arang tempurung kelapa dan arang bamboo memenuhi standar mutu briket berdasarkan SNI No 1/6235/2000 yaitu $5000 \mathrm{kal} / \mathrm{g}$. Hal ini menunjukkan bahwa pembuatan briket kombinasi tempurung kelapa dan bambu dengan menggunakan ukuran partikel 40 mesh dapat menggunakan perbandingan komposisi 10\%:90\%, 20\%:80\%, 30\%:70\%, dan 40\%:60\%, meskipun kondisi optimum diperoleh pada komposisi 10\%;90\%.

\section{Kadar air briket}

Hasil pengukuran kadar air briket kombinasi arang tempurung kelapa dan arang bambu ditunjukkan pada Gambar 3. Seperti halnya nilai kalor, kadar air merupakan parameter penting yang harus diketahui dalam pembuatan briket. Kadar air yang tinggi akan mempengaruhi parameter kualitas briket yang lain seperti nilai kalor, kemudahan menyala dan jumlah asap yang dihasilkan. 
Berdasarkan Gambar 3 terlihat bahwa dengan penambahan tempurung kelapa menyebabkan nilai kadar air semakin kecil. Hal ini disebabkan karena dengan penambahan tempurung kelapa berarti terjadi pengurangan arang bambu. Pengurangan arang bambu berarti memperkecil daya serap sehingga kadar air semakin berkurang. Semua sampel memenuhi SNI untuk parameter kadar air. Dimana kadar air berdasarkan SNI mutu briket adalah maksimal $8 \%$ dan semua sampel memiliki kadar air kurang dari $8 \%$. Kadar air terendah diperoleh pada komposisi 10\%:90\% yaitu sebesar 3,8\%.

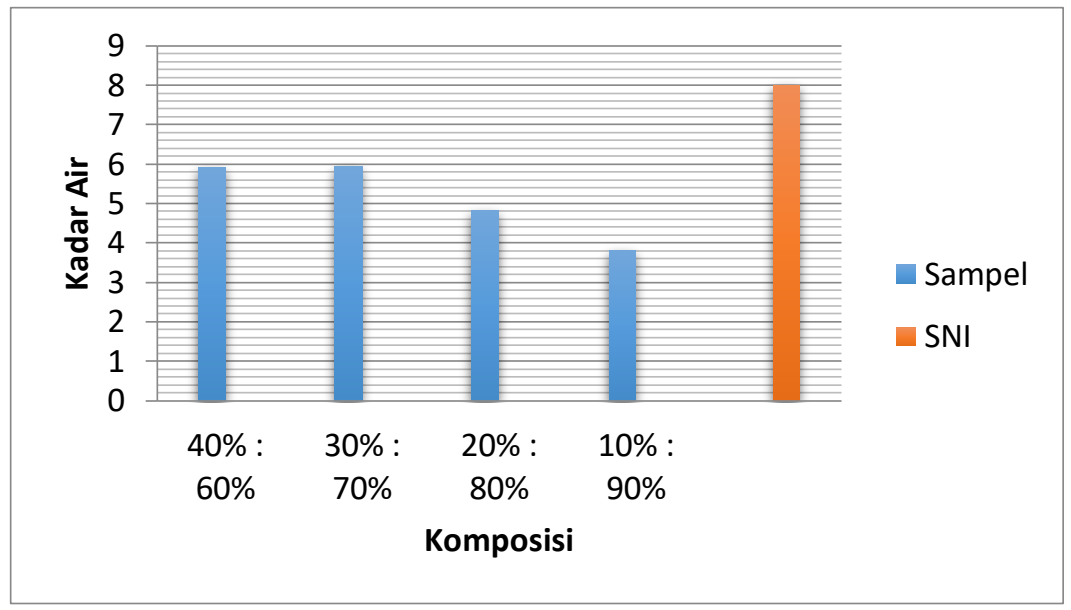

Gambar 3. Grafik hubungan antara komposisi briket terhadap kadar air pada ukuran partikel yang berbeda

3. Lama waktu penyalaan briket berikut:

Hasil pengukuran lama waktu penyalaan briket ditunjukkan pada Gambar 4

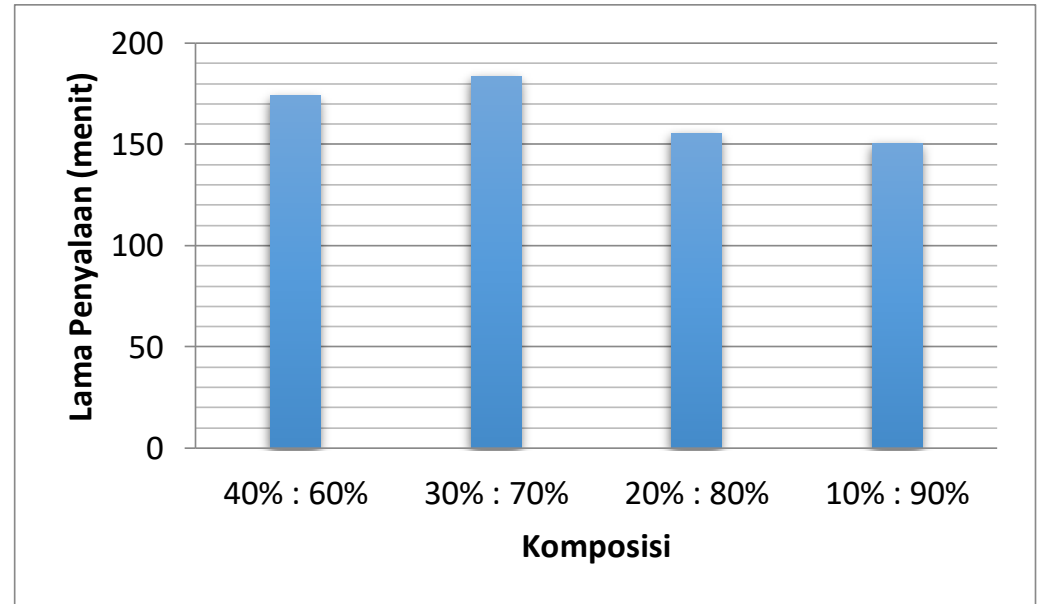

Gambar 4. Grafik hubungan antara komposisi briket terhadap lama penyalaan pada ukuran partikel yang berbeda 
Berdasarkan grafik pada Gambar 4, terlihat bahwa komposisi tidak signifikan mempengaruhi lama penyalaan briket. Meskipun demikian, lama penyalaan yang terbesar adalah pada komposisi 30\%:70\% yaitu 183,55 menit. Lama penyalaan briket dipengaruhi oleh ukuran partikel. Semakin kecil ukuran partikel, maka lama penyalaannya semakin besar untuk semua komposisi yang digunakan. Waktu penyalaan yang terbesar diperoleh pada ukuran partikel 170 mesh (Ihsan, 2018). Semakin kecil ukuran partikel, maka kerapatan massanya akan semakin besar, akibatnya perpindahan panas secara konduksi akan mudah terjadi dari partikel yang satu ke partikel yang lainnya yang menyebabkan waktu penyalaan briket menjadi besar.

\section{KESIMPULAN}

Berdasarkan hasil penelitian yang telah dilakukan, dapat disimpulkan bahwa variasi komposisi briket dari arang tempurung kelapa dan arang bambu mempengaruhi karakteristik briket yaitu nilai kalor, kadar air, dan lama waktu penyalaan. Nilai kalor tertinggi diperoleh pada komposisi $10 \%$ arang bambu dan $90 \%$ arang tempurung kelapa adalah $7110,73 \mathrm{kal} / \mathrm{g}$ dengan kadar air sebesar $4,82 \%$ dan lama waktu penyalaan 150,45 menit.

\section{DAFTAR PUSTAKA}

Arni L, Hosiana MD, Nismayanti A. 2014. Studi uji karakteristik fisis Briket bioarang sebagai sumber energi alternatif. Journal of Natural Science. 3(1): 89-98

Budi NW dkk., 2016. Penggunaan tongkol jagung dalam meningkatkan nilai kalor pada briket. Jurnal Integrasi Proses vol 6(1): 16-21.

Ihsan, dkk., 2019. Pengaruh ukuran partikel terhadap karakteristik briket kombinasi arang bambu dan arang tempurung kelapa. Laporan penelitian.

Julham Prasetya, dkk. 2015. Pengaruh Konsentrasi Perekat Tepung Tapioka Dan Penambahan Kapur Dalam Pembuatan Briket Arang Berbahan Baku Pelepah Aren. Departemen Teknik Kimia, FakultasTeknik, Universitas Sumatera Utara.

Kompas, 2016. Mitos atau Fakta, Indonesia Kaya Migas? Kompas.com, 19 Agustus 2016.

Monica CR dkk, 2012. Pembuatan briket arang dari limbah organik dengan menggunakan variasi komposisi dan ukuran bahan. Prosiding Seminar Nasional Kimia dan Pendidikan Kimia,UNS surakarta.

Qistina Idzni dkk, 2016. Kajian Kualitas Briket Biomassa dari Sekam Padi dan Tempurung Kelapa. Jurnal Kimia Valensi. 2(2): 136-142. 
Thoha Yusuf. 2013. Pembuatan Briket Arang Dari Daun Jati Dengan Sagu Aren Sebagai Pengikat. Jurusan Teknik Kimia. Fakultas Teknik Universitas Sriwijaya.

Siahaan S dkk., 2013. Penentuan kondisi optimum suhu dan waktu karbonisasi pada pembuatan arang dari sekam padi. Jurnal Teknik Kimia USU. 1(2).

Sinurat E. 2011. Studi pemanfaatan briket kulit jambu mete dan tongkol jagung sebagai bahan bakar alternatif. Makasar: Universitas Hasanudin.

Satmoko, M.E.A, dkk. 2013. Karakteristik Briket dari Limbah Pengolahan Kayu Sengon dengan Metode Cetak Panas, Univeristas Negeri Semarang, Semarang, 2013, 2(1).

Sucipto, C.D., 2012. Teknologi Pengelolaan Daur Ulang Sampah, Gosyen Publishing, Yogyakarta.

Sudiro, S. S., 2014. Pengaruh Komposisi dan Ukuran Serbuk Briket yang Terbuat dari Batubara dan Jerami Padi Terhadap Karakteristik Pembakaran, Politeknik Indonusa, Surakarta, 2014, 02(02). 